\title{
Desnutrição energético-protéica e cárie dentária na primeira infância
}

\author{
Protein-energy malnutrition and \\ early childhood caries
}

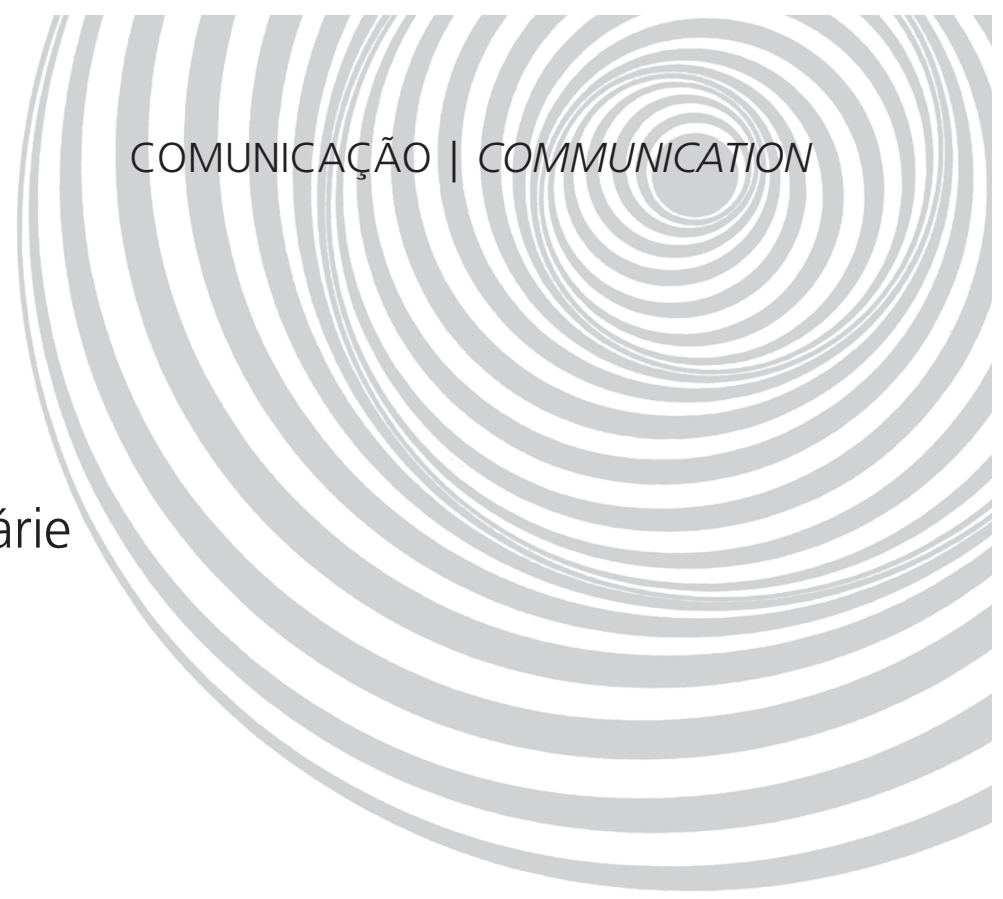

Dijane Pereira COSTA ${ }^{1}$

Ana Catarina de Miranda MOTA ${ }^{1}$

Glaucenira de Barros BRUNO'

Maria Eneide Leitão de ALMEIDA'

Cristiane Sá Roriz FONTELES ${ }^{1}$

\section{R E S U M O}

Este estudo tem por objetivo investigar a relação existente entre a desnutrição energético-protéica e a cárie dentária precoce na primeira infância. Trata-se de uma comunicação, para a qual foi realizada uma revisão da literatura, a partir de análise documental de produção bibliográfica, baseada em levantamentos de periódicos e consultas a livros. Verificou-se que a cárie precoce na infância é altamente prevalente nas comunidades de baixa renda, nas quais a desnutrição é um fator comum e de grande relevância. Estudos mostram que crianças desnutridas tendem a apresentar defeitos estruturais no esmalte do dente, como também estão predispostas a um maior risco à cárie dentária. Portanto, uma deficiência energético-protéica durante a fase de desenvolvimento dentário (odontogênese) tem demonstrado uma maior suscetibilidade à cárie dentária, atraso na cronologia de erupção e defeitos estruturais do esmalte (hipoplasia de esmalte), hipofunção das glândulas salivares e mudança na composição da saliva. Estes fatores podem ser os mecanismos pelos quais a desnutrição associa-se à cárie. Em conclusão, os estudos sugerem que a deficiência energético-protéica durante a odontogênese gera atraso na cronologia de erupção e defeitos estruturais no esmalte (hipoplasia), além de poder afetar as glândulas salivares, aumentando o risco de ocorrência da doença cárie. Estudos investigando associações entre desnutrição e cárie na primeira infância são de grande relevância para ampliar o conhecimento desta doença e o desenvolvimento de ações de promoção e de prevenção desse problema de saúde pública com aplicações nas áreas de nutrição e odontologia.

Termos de indexação: Desnutrição. Cárie dentária. Criança. Odontogênese

A B S T R A C T

This study aimed to investigate the relationship between protein-energy malnutrition and early childhood caries. For this communication, a review of the literature was performed, based on documental analysis of

\footnotetext{
1 Universidade Federal do Ceará, Faculdade de Farmácia, Odontologia e Enfermagem, Departamento de Clínica Odontológica. R. Monsenhor Furtado, s/n., Rodolfo Teófilo, 60441-750, Fortaleza, CE, Brasil. Correspondência para/Correspondence to: D.P. COSTA. E-mail: <dijanecosta@yahoo.com.br>.
} 
bibliographic searches, surveys of scientific journals and books. Early childhood caries was found to be highly prevalent in low income communities, where malnutrition is a common factor of great relevance. Studies have shown that malnourished children have a tendency to develop structural enamel defects, which predisposes towards a higher risk of experiencing dental caries. Therefore, protein-energy malnutrition during tooth development (odontogenesis) is associated with increased caries susceptibility, delayed eruption and structural enamel defects (enamel hypoplasia). In conclusion, the studies suggest that protein-energy malnutrition during odontogenesis leads to delayed eruption and structural enamel defects (hypoplasia), in addition to possibly affecting the salivary glands, increasing the risk for dental caries. Studies investigating associations between malnutrition and caries in early childhood are of great relevance to expand the knowledge on this illness and the development of health-promoting and preventive activities for this public health problem, with a vast repercussion in the fields of nutrition and dentistry.

Indexing terms: Malnutrition. Dental caries. Child. Odontogenesis.

\section{N T R O D U ÇÃ O}

Para a realização do metabolismo nos seres vivos saudáveis há necessidade de nutrientes e de energia que estão disponíveis nos alimentos ${ }^{1}$. De acordo com Bailey², os alimentos são constituídos de vários nutrientes, entre os quais aqueles que são passíveis de reações catabólicas com posterior geração de energia, sendo chamados de nutrientes energéticos, como as proteínas, os carboidratos e os lipídeos.

A nutrição está relacionada ao equilíbrio entre a alimentação e o gasto fisiológico de energia e nutrientes de todas as células do corpo, inclusive as responsáveis pela formação do tecido dentário, da saliva e do epitélio oral. Distúrbios nutricionais que podem ocorrer no período de formação do feto, bem como no balanço energético-protéico, afetam a formação do tecido dentário de acordo com suas funções biológicas gerais. As alterações nutricionais, principalmente relacionadas à síntese protéica ou à mineralização, podem culminar em alterações estruturais dos tecidos dentários, bem como da forma, da posição e do tempo de erupção ${ }^{3}$. Quando as proteínas deixam de desempenhar seus papéis estruturais e enzimáticos passando a assumir a provisão de glicose e energia para o organismo, instala-se um estado de desequilíbrio metabólico, e quanto mais tempo durar esse desequilíbrio maiores os danos para o indivíduo que poderá apresentar quadros de anemias, hipovitaminoses e desnutrição energético-protéica, sendo este último um dos problemas de saúde publica brasileiros, especialmente em áreas mais pobres ${ }^{4,5}$.

A Desnutrição Energético-Protéica (DEP) ocorre quando existe deficiência no consumo de proteínas e energia com relação às necessidades do corpo ${ }^{6}$. Esta é uma das mais comuns deficiências nutricionais, vitimando cerca de 150 milhões de crianças menores de 5 anos no mundo 7 . A prevalência da desnutrição na população infantil brasileira menor de 5 anos, aferida pela proporção de crianças com déficit de crescimento, foi de $7 \%$ em 2006, destacando-se quanto à distribuição espacial indica uma freqüência máxima na Região Norte (15\%), e pouca variação entre as demais regiões ${ }^{8}$. Duas condições intimamente relacionadas com o padrão de vida da população, consumo alimentar inadequado e infecções de repetição, nas quais se inclui o acesso à alimentação, à moradia e à assistência à saúde, relacionam-se com a DEP9. A desnutrição energética proteica em seus diferentes estágios, desde as formas mais leves, capazes de expressar déficits discretos do crescimento ou pequenas perdas de peso, até as manifestações mais graves, como o Kwashiorkor (desnutrição edematosa) e o marasmo, constitui-se uma das mais difundidas doenças carenciais, e um dos maiores problemas de saúde coletiva em países em desenvolvimento ${ }^{10}$.

O Kwashiorkor e o marasmo se manifestam clinicamente de forma distinta. As principais características do Kwashiorkor são retardo no crescimento, perda de gordura subcutânea e 
muscular, menos intensa do que no marasmo, edema depressível que se localiza, principalmente, nas pernas, mas que pode atingir todo o corpo, bem como alterações mentais e de humor. Tanto o couro cabeludo, como as alterações nos cabelos (textura, cor, perda de brilho e queda), generalizadas ou localizadas (sinal da bandeira), como o tecido cutâneo, com lesões de despigmentação e descamação, podem estar afetados. Sintomas como anorexia, diarréia, infecções e deficiências (vitamina A, zinco e ferro) são também frequentemente encontradas. Um significante grau de perda de peso e a presença de edema são os aspectos essenciais para o diagnóstico de Kwashiorkor ${ }^{11}$. Ademais, o baixo peso ao nascer (<2 500g) pode ser tomado como um bom indicador do risco da desnutrição materno-fetal. Nos países com boas condições de saúde e nutrição, menos de $8 \%$ das crianças nascidas vivas têm peso inferior a 2 500g, em contrapartida nas áreas de pobreza, estes índices crescem para 30\% dos nascimentos ocorridos ${ }^{12}$.

Quanto à origem, a DEP caracteriza-se como primária (dieta deficiente) ou secundária (dieta condicionada). Enquanto na desnutrição primária o consumo inadequado de nutrientes é o fator determinante desta morbidade, a secundária é causada por outros fatores, diferentes da dieta, como, por exemplo, a absorção e utilização dos nutrientes ${ }^{13}$. Portanto, o indivíduo desnutrido é aquele cujas células não recebem os nutrientes de que necessita para desempenhar suas funções de produção energética, formação ou reparação tecidual e regulação do seu próprio funcionamento ${ }^{13}$.

A deficiência nutricional na primeira infância pode impactar em diversos destes fatores, com potencial de alterar as condições presentes no ambiente da cavidade oral. O presente trabalho tem por objetivo abordar estas duas condições: assim, serão discutidos os diversos fatores alterados pela DEP, capazes de resultar nos riscos de desenvolvimento da cárie precoce da infância.

\section{ERUPÇÃ O DENTÁ RIA}

A odontogênese (formação dental) na dentição humana começa no período intrauterino e a formação do esmalte (amelogênese) ocorre em três fases distintas: deposição da matriz do esmalte; calcificação (quando os minerais são depositados e as proteínas removidas) e maturação ${ }^{14}$. As causas da má formação dental são várias, sendo a nutrição apenas uma delas. Tanto a dentição decídua como a dentição permanente podem ser afetadas, sendo que a época da agressão está determinada pela localização do defeito na coroa dental uma vez que o processo de esfoliação e/ou erupção segue uma cronologia bem definida ${ }^{15}$.

Existem evidências de que a desnutrição pode conduzir ao retardo da erupção dos dentes decíduos. Infante \& Gillespie ${ }^{16,17}$; Alvarez \& Navia18; Alvarez et al. ${ }^{19,20}$ e Duarte ${ }^{21}$; verificaram que a desnutrição retarda a cronologia de erupção dentária, o que implica dizer que crianças desnutridas têm seus dentes expostos ao meio bucal mais tardiamente. Segundo Alvarez ${ }^{22}$, este atraso de erupção alteraria o padrão de desenvolvimento da cárie dentária, uma vez que a colonização da cavidade oral por Estreptococos do Grupo Mutans (EGM) ocorre após a erupção do primeiro dente. Isto porque se faz necessária a presença de uma superfície que permita a organização de um biofilme cariogênico ${ }^{23}$.

\section{HIPOPLASIA DO ESMALTE}

A hipoplasia de esmalte pode ser definida como um defeito que envolve a superfície do esmalte, associado a uma redução em sua espessura, com a presença de sulcos ou depressões. Em contrapartida, a opacidade (ou hipocalcificação) é definida como um defeito qualitativo, identificado visualmente como uma anormalidade na translucidez do esmalte, com áreas branco-opacas, amareladas ou acastanhadas, sem perda de continuidade da superfície afetada ${ }^{24,25}$. 
Infante \& Gillespie ${ }^{16,17}$ observaram em seus estudos que a desnutrição predispunha ao aparecimento de hipoplasia de esmalte linear. Alguns anos mais tarde, Suckling et al. ${ }^{26}$ verificaram uma associação entre hipoplasia do esmalte e desnutrição. Sawyer \& Nwoku ${ }^{27}$ pesquisaram o nível de saúde oral em 52 crianças com desnutrição severa, com idades variando de 1 a 5 anos, oriundas de uma área rural da Nigéria. Os autores encontraram hipoplasia de esmalte em $18,6 \%$ das crianças desnutridas, enquanto que, no grupo com ausência de desnutrição, não houve registro dessa alteração. Segundo Li et al. ${ }^{28}$, a prematuridade aliada a um baixo peso ao nascer gera uma associação significativa ao desenvolvimento de hipoplasia de esmalte, um importante fator para o início e a progressão da cárie dentária. De fato, Batista et al. ${ }^{29}$ em trabalho de revisão sobre a alimentação, o estado nutricional e a condição bucal da criança, concluíram que as deficiências nutricionais no período de formação dentária são causas de defeitos na estrutura do dente, tendo potencial para alterar sua forma e atuar na quantidade e na qualidade da saliva, influenciando no processo de formação da cárie dentária.

\section{H I P O F U C Ã O D A S GLÂDULASSALIVARES}

A saliva é o principal fator do hospedeiro capaz de fornecer proteção às estruturas dentárias, impedindo o desenvolvimento da doença cárie $^{30-32}$. Dentre as muitas propriedades inerentes ao fluido salivar encontram-se: um sistema tampão com capacidade neutralizadora dos áci$\operatorname{dos}^{30,31,33 \text {; funções remineralizadoras }}{ }^{30,31,34}$ e de retardo da desmineralização do esmalte ${ }^{30,32,33}$. Ademais, seus fatores antimicrobianos constituem a primeira linha de defesa da cavidade oral ${ }^{30-34}$; presentes na placa bacteriana ${ }^{30,32}$ e na película dental, conferindo proteção contra agressões químicas e físicas ${ }^{30,31,33}$. A hipofunção das glândulas salivares pode ser definida pela redução do fluxo salivar, da capacidade tampão e dos constituintes salivares, principalmente as proteínas ${ }^{35}$, o que predispõe a uma maior prevalência de cárie dentária. Há um número pequeno de estudos investigando desnutrição e hipofunção salivar em seres humanos.

Em 1977, McMurray et al. ${ }^{36}$ verificaram em população de crianças colombianas desnutridas a redução nos níveis de imunoglobulina $A$. Os componentes salivares de crianças egípcias, normais e desnutridas, foram estudados, tendose observado nos casos edematosos, aumento nos níveis dessas moléculas. Contudo, nos casos não-edematosos grau II, a redução destes constituintes foi observada. Assim, os autores sugeriram ser a elevação das proteínas salivares nos casos edematosos o possível resultado de um severo envolvimento glandular ${ }^{37}$. Ao examinar uma população de 94 crianças indianas, eutróficas e desnutridas, Agarwal et al. ${ }^{38}$ encontraram níveis diminuídos de proteínas salivares em função da severidade da desnutrição. A comparação entre crianças gambianas e britânicas, levou à identificação de níveis reduzidos de imunoglobulina $A$, sendo o fato atribuído às diferenças nutricionais entre os grupos estudados ${ }^{39}$.

Johansson et al. ${ }^{40}$, estudando crianças indianas não desnutridas e outro grupo com desnutrição moderada, verificaram que o fluxo de secreção salivar estimulada estava diminuído na população desnutrida, fato não observado com relação à saliva não estimulada. Outro dado de importância descrito foi a redução na capacidade tampão salivar segundo o grau de desnutrição identificado. Em 1994, Johansson et al. ${ }^{41}$, estudando a composição salivar em crianças com desnutrição crônica, mais uma vez encontraram redução do fluxo de secreção salivar estimulado e da capacidade tampão. Segundo os autores, as crianças com desnutrição moderada ou severa tiveram também diminuição dos íons cálcio e da secreção de proteínas na saliva estimulada. Houve prejuízo imunológico para as crianças desnutridas, com reduzida aglutinação dos fatores de defesa na saliva não estimulada. 


\section{CÁRIE DENTÁRIA}

Cárie de Primeira Infância (CPI) é uma doença infecciosa e transmissível na dentição decídua, com uma etiologia complexa e multifatorial, envolvendo microorganismos cariogênicos, carboidratos fermentáveis e superfícies dentárias suscetíveis ${ }^{42}$. A cárie dentária se constitui um grande problema de saúde pública nos países subdesenvolvidos ${ }^{43}$ e no Brasil. A dentição decídua é uma doença comum e de natureza agressiva, denominada cárie precoce da infância, cuja prevenção pode ser iniciada nos primeiros anos de vida, no consultório odontológico ${ }^{44}$. Como outros tipos de cárie dentária, a CPI é causada por estreptococos do grupo mutans, que fermentam carboidratos da dieta, produzindo ataque ácido a dentes susceptíveis, durante um determinado período de tempo. Possivelmente a imaturidade do sistema imune aliada à ineficácia na higienização da cavidade oral, hábitos alimentares indevidos e as propriedades estruturais de dentes recém-erupcionados confere à $\mathrm{CPI}$ o caráter agressivo e de rápido desenvolvimento característico da doença ${ }^{45}$.

Dados reportados nos Estados Unidos relatam uma prevalência de cárie dentária cinco vezes maior do que a da asma, e sete vezes maior do que a da rinite alérgica ${ }^{46,47}$, afetando $80 \%$ da população infanto-juvenil americana, sendo também considerada a quinta doença mais onerosa ao tratamento no Reino Unido ${ }^{48}$. No Brasil, constitui-se o principal agravo com que se defronta a odontologia social. Quase $27 \%$ das crianças, de 18 a 36 meses apresentam pelo menos um dente decíduo com experiência de cárie, chegando à proporção de quase $60 \%$ das crianças com 5 anos de idade ${ }^{49}$.

Poucos estudos têm mostrado associação entre desnutrição e cárie dentária. Infante \& Gillespie $^{16}$ em 1976, examinando 528 crianças com desnutrição moderada de 1 a 6 anos de idade da zona rural da Guatemala, encontraram duas vezes mais cáries do que em crianças americanas brancas da mesma faixa etária. Em 1977, os autores em um outro estudo, puderam observar que crianças com Hipoplasia de Esmalte Linear (HEL) tinham maior experiência de cárie nos dentes posteriores do que as crianças que não apresentavam HEL, sugerindo um sinergismo entre desnutrição e infecção, podendo predispor ao aparecimento de $\mathrm{HEL}^{17}$.

Alvarez et al. ${ }^{50}$, em 1988, examinando 285 crianças peruanas de 3 a 9 anos de idade, observaram que a desnutrição crônica tornava os dentes decíduos mais susceptíveis ao aparecimento de cárie, e afetava a esfoliação dos mesmos. Em 1990, Alvarez et al. ${ }^{19}$, examinando 1481 crianças peruanas de 1 a 13 anos de idade, concluíram haver atraso no desenvolvimento dentário ocasionado pela desnutrição, podendo a mesma também afetar a distribuição da cárie dentária por idade, resultando em um aumento da experiência de cárie na dentição decídua. O estudo de 209 crianças peruanas confirmou que existe uma relação de causa e efeito entre desnutrição precoce e aumento de cárie dentária ${ }^{20}$. Em 1995, Alvarez ${ }^{22}$ relatou que um único episódio de desnutrição leve ou moderada no primeiro ano de vida possui a capacidade de aumentar a manifestação da cárie dentária tanto na dentição decídua, como anos depois na dentição permanente.

Johansson et al..$^{40}$, examinando crianças indianas normais e com desnutrição moderada, encontraram um maior número de lesões cariosas entre crianças desnutridas. Os autores concluíram que a desnutrição crônica na infância em fase de crescimento, aumentaria o potencial cariogênico oriundo dos carboidratos fermentáveis da dieta. A pesquisa de 1994 confirmou esses achados ${ }^{41}$. Li et al. ${ }^{28}$, estudando 1344 crianças chinesas da zona rural puderam observar que a deficiência nutricional tem um importante impacto no desenvolvimento dentário e suscetibilidade à cárie.

Recentemente, Oliveira et al..$^{51}$ estudaram a relação entre estado nutricional e cárie em 1018 crianças brasileiras pré-escolares, com idades entre 12 e 59 meses. Os autores verificaram uma associação significativa entre estado nutricional e experiência de cárie, com um aumento no risco de cárie na presença de uma redução importante nos 
seguintes indicadores: índice de massa corporal para a idade, peso para a altura e peso para a idade. No referido estudo, crianças com baixo peso para a idade apresentaram uma maior probabilidade de desenvolver CPI severa, ou seja, de apresentar um maior número de superfícies dentárias cariadas, restauradas ou perdidas devido à cárie.

\section{CONSIDERAÇÕ ES FINAIS}

O exame da literatura levou às seguintes conclusões: a dieta e a nutrição desempenham um papel significativo no desenvolvimento dentário e na integridade dos tecidos orais; a deficiência energético-protéica durante a fase de desenvolvimento dentário (odontogênese) gera atraso na cronologia de erupção e defeitos estruturais no esmalte (hipoplasia), com aumento do risco de ocorrência da doença cárie e ainda, a desnutrição pode afetar as glândulas salivares, por meio da redução de seu fluxo e da alteração da composição da saliva, aumentando assim a susceptibilidade dos dentes às lesões de cárie. Observou-se também que a cárie precoce da infância é bastante frequente em comunidades de baixa renda, entre as quais a desnutrição pode ser um agravante.

Desse modo, estudos investigando tais associações na primeira infância são relevantes para ampliar o conhecimento desta doença e o desenvolvimento de ações de promoção e de prevenção deste problema de saúde pública, com aplicações nas áreas de nutrição e odontologia.

\section{OLABORADORES}

D.P. COSTA responsável pelo processo de revisão da literatura na área de cárie precoce da infância (CPI) e desnutrição. Confecção do manuscrito. Parte deste trabalho foi extraída de seu projeto de tese. A.C.M. MOTA colaborou com a revisão da literatura sobre a relação entre desnutrição e saliva e com a confecção do manuscrito. G.B. BRUNO como coordenadora do projeto de extensão da UFC no IPREDE (Instituto de Prevenção à Desnutrição e Excepciona- lidade) contribuiu com a revisão de literatura sobre erupção dentária, hipoplasia de esmalte e cárie de primeira infância e participou da confecção do manuscrito. M.E.L ALMEIDA co-orientadora do trabalho. Colaborou com a correção do manuscrito. C.S.R. FONTELES orientadora do trabalho e das teses acima referidas. Coordenou a confecção do manuscrito, desde seu processo inicial de revisão até a correção da versão final.

\section{REFERÊ N CIAS}

1. Cuppari L. Nutrição clínica no adulto. São Paulo: Manole; 2002. p.406.

2. Baley LB. New standard for dietary folate in pregnant womem. Am J Clin Nutr. 2000; 71(5): 13045-75.

3. Cutinho L. Odontologia para gestantes, 2006. [acesso 2006 maio]. Disponível em: <http:// www.clubedobebe.com.br/odontopediatria.htm>.

4. Nunes ML, Batista BB, Micheli F, Batistela V. Efeitos da desnutrição precoce e reabilitação em ratos. J. Pediatr. 2002; 77(1):39-44.

5. Ribeiro AG, Oliveira AF, Rosenblat $A$. Cárie precoce na infância: prevalência e fatores de risco em préescolares, aos 48 meses, na cidade de João Pessoa, Paraíba, Brasil. Cad Saúde Pública. 2005; 21(6): 1695-700.

6. Shils ME, Olson JA, Moshe S. modern nutrition in health and disease. $9^{\text {nd }}$ ed. Philadelphia: Lippincott, Williams and Wilkins; 1999.

7. World Health Organization. Department of Nutrition for Health and Development. Nutrition for health and development: a global agenda for combating malnutrition. [cited 2008 Jun 5]. Available from: <http://whqlibdoc.who.int/hq/ 2000/WHO_NHD_00.6.pdf >.

8. Política Nacional de Demografia e Saúde. [acesso 2008 out 31]. Disponível em: <http://bvsms. saude.gov.br/bvs/pnds/saude_nutricional.php>.

9. Devincenzi MU, Lessa AC, Sigulem DM. Nutrição em saúde pública. In: Lopez FA, Brasil ALD. Nutrição e dietética em clínica pediátrica. São Paulo: Atheneu; 2004. p.127-37.

10. Batista FM. Alimentação, nutrição e saúde. In: Rouquayrol MZ, Almeida Filho N. Epidemiologia e saúde. $6^{a}$ ed. Rio de Janeiro: Medsi; 2003. p. 389-414.

11. Organização Mundial de Saúde. Manejo da desnutrição grave: um manual para profissionais de saúde de nível superior (médicos, enfermeiros, 
nutricionistas e outros) e seus auxiliares. Genebra: Organização Mundial da Saúde; 2000.

12. Fundo das Nações Unidas para a Infância. Situação mundial da infância, 1998: a nutrição em foco. Brasília; 1998.

13. Borsoi MA. Nutrição e dietética: noções básicas. São Paulo: Senac; 2001.

14. Braido CA, Yassuda LYW. Anormalidades de calcificação dentária (hipoplasia de esmalte). Ped Mod. 1991; 26(2):103-16.

15. Gonçalves AF, Ferreira SLM. Defeitos hipoplásicos do esmalte dentário. Rev Odonto Univ Santo Amaro. 2000; 5(1):13-20.

16. Infante PF, Gillespie GM. Dental caries experience in the deciduous dentition of rural Guatemalan children ages 6 months to 7 years. J Dent Res. 1976; 55(6):951-7.

17. Infante PF, Gillespie GM. Enamel hypoplasia in relation to caries in Guatemalan Children. J Dent Res. 1977; 56(5):493-8.

18. Alvarez J, Navia JM. Nutricional status, tooth eruption, and dental caries. Am J Clin Nutr. 1989; 49(3):417-26.

19. Alvarez JO, Eguren JC, Caceda J, Navia JM. The effect of nutritional status on the age distribution of dental caries in the primary teeth. J Dent Res. 1990; 69(9):1564-6.

20. Alvarez JO, Caceda J, Woolley TW, Carley KW, Baiocchi N, Caravedo L, et al. A longitudinal study of dental caries in the primary teeth of children who suffered from infante malnutrition. J Dent Res. 1993; 729(12):1573-6.

21. Duarte RC. Prevalência de cárie na dentição decídua em crianças nutridas e desnutridas da Grande João Pessoa com base no índice CEO-S [dissertação]. Recife: Universidade de Pernambuco; 1992.

22. Alvares JO. Nutrition, tooth development, and dental caries. Am J Clin Nutr. 1995; 61(2):410S-6S.

23. Caufield PW, Cutter GR, Dasanayake AP. Initial acquisition of mutans streptococci by infants: evidence for a discrete window of infectivity. J Dent Res. 1993; 72(1):37-45.

24. Seow WK. Enamel hipoplasia in the primary dentition: a review. ASDC J Dent Child. 1991; 58(6):441-52.

25. Aine L, Backstrom MC, Maki R, Kuusela AL, Koivisto AM, Ikonen RS et al. Enamel defects in primary and permanent teeth of children born prematurely. J Oral Pathol Med. 2000; 29(8):403-9.

26. Suckling G, Elliott DC, Thurley DC. The production of developmental defects of enamel in the incisor teeth of penned sheep resulting from induced parasitism. Arch Oral Biol. 1983; 28(5):393-9.
27. Sawyer DR, Nwoku AL. Malnutrition and the oral health of children in Ogbomosho, Nigeria. ASDC J Dent Child. 1985; 52(2):141-5.

28. Li Y, Navia JM, Bian JY. Caries experience in deciduous dentition of rural Chinese children 3-5 years old in relation to the presence or absence of enamel hipoplasia. Caries Res. 1996; 30(1): 8-15.

29. Batista LRV, Moreira EAM, Corso ACT. Alimentação, estado nutricional e condição bucal da criança. Rev Nutr. 2007; 20(2):191-6. doi: 10.1590/\$14 15-S2732007000200008.

30. Farias DG, Bezerra ACB. Salivary Antibodies, amylase and protein from children with early childhood caries. Clin Oral Investig. 2003; 7(3): 154-7.

31. van Nieuw Amerongen A, Bolscher JGM, Veerman $\mathrm{ECl}$. Salivary proteins: protective and diagnostic value in cariology? Caries Res. 2004; 38(3): 247-53.

32. Simmonds, RS, Tompikins GR, George RJ. Dental caries and the microbial ecology of dental plaque: a review of recent advances. N Z Dent J. 2000; 96 (424):44-9.

33. Lagerlöf F, Oliveby A. Caries-protective factors in saliva. Adv Dent Res. 1994; 8(2):229-38.

34. Denny PC, Denny PA, Klauser DK, Hong SH, Navazesh M, Tabak LA. Age-related changes in mucins from human whole saliva. J Dent Res. 1991; 70(10):1320-7.

35. Psoter WJ, Reid BC, Katz RV. Malnutrition and dental caries: a review of the literature. Caries Res. 2005; 39(6):441-7.

36. McMurray DN, Rey H, Casazza L, Watson RR. Effect of moderate malnutrition on concentrations of immunoglobulins and enzymes in tears and saliva of young Colombian children. Am J Clin Nutr. 1977; 30(12):1944-8.

37. Ibrahim AM, EL-Hawary MF, Sakr R. Protein-calorie malnutrition (PCM) in Egypt immunological changes of salivary protein in PCM. Z Ernahrungswiss. 1978; 17(3):145-52.

38. Agarwal PK, Agarwal KN, Agarwal DK. Biochemical changes in saliva of malnourished children. Am J Clin Nutr. 1984; 39(2):181-4.

39. Azzopardi D, Watson JG. Gambian children have less salivary secretory immunoglobulin $A$ than British children. J Trop Pediatr. 1986; 32(3):120-2.

40. Johansson I, Saellstron AK, Rajan BP, Parameswaran A. Salivary flow and dental caries in Indian children suffering from chronic malnutrition. Caries Res. 1992; 26(1):38-43.

41. Johansson I, Lenander-Lumikari M, Saellström AK. Saliva composition in Indian children with chronic 
protein-energy malnutrition. J Dent Res. 1994; 73(1):11-9.

42. Ramos-Gomez FJ, Weinntraub JA, Gansky AS, Hoover $\mathrm{Cl}$, Featherstone JDB. Bacterial, behavioral and environmental factors associated with early childhood caries. J Clin Pediatr Dent. 2002; 26(2): 165-73.

43. Maciel SSSV. Prevalência de cárie nas crianças de 7 a 48 meses de idade, da Clínica Odontológica do Verdão, Distrito Sanitário Oeste, Cuiabá, 1998 [monografia]. Cuiabá: Universidade Federal de Mato Grosso; 1998.

44. Krol DM. Educating pediatricians on children's oral health: past, present, and future. Pediatrics. 2004; 113(5):E487-92.

45. Seow WK. Biological mechanisms of early childhood caries. Community Dent Oral Epidemiol. 1998; 26(1 Suppl):8-27.

46. Pierce KM, Rozier RG, Vann WF. Accuracy of pediatric primary care providers screening and refferal for early childhood caries. Pediatrics. 2002; 109(5): E82-2.
47. Hale KJ. American Academy of Pediatrics Section on Pediatric Dentistry. Oral health risk assessment timing and establishment of the dental home. Pediatrics. 2003; 111(5 Pt 1):1113-6.

48. Maia MCG, Sampaio HAC, Silva CAB. Saúde bucal coletiva: metodologia de trabalho e práticas. São Paulo: Santos; 2006. p.139-53.

49. Brasil. Ministério da Saúde, Projeto SB Brasil 2003 condições de saúde bucal da população brasileira. 2002-2003: resultados principais. Brasília; 2004.

50. Alvarez JO, Lewis CA, Saman C, Caceda J, Montalvo J, Figueiroa ML. Chronic malnutrition, dental caries, and tooth exfolation in Peruvian children aged 39 years. Am J Clin Nutr. 1988; 48(2):368-72.

51. Oliveira LB, Sheiham A, Bonecker M. Exploring the association of dental caries with social factors and nutritional status in Brazilian preschool children. Eur J Oral Sci. 2008; 116(1):37-43.

Recebido em: 12/3/2008

Versão final reapresentada em: 3/4/2009 Aprovado em: 6/10/2009 